Gut, 1975, 16, 689-692

\title{
Postoperative motility of the large intestine in man
}

\author{
J. P. WILSON \\ From Queen Mary's Hospital, Sidcup, Kent
}

SUMMARY Motor activity of the colon in the immediate postoperative period has been studied in human subjects using radiotelemetering capsules, radioopaque markers and serial abdominal radiographs.

Following operations outside the abdomen there is a delay of about 16 hours before colonic activity returns. After abdominal operations the delay is from 40 to 48 hours.

The length of an operation has no significant effect upon the duration of colonic ileus.

The amount of postoperative analgesia has no significant effect upon the duration of colonic ileus.

Gaseous distension after laparotomy is confined to the colon.

It is well recognized that following operation the motility of the gastrointestinal tract is temporarily impaired. At times this is more prolonged and, if associated with gaseous distension, develops into paralytic ileus.

It has been shown in experimental animals that the activity of the small intestine returns to normal within a few hours following surgery (Tinckler, 1965; Baker and Webster, 1968). Early return of activity has also been shown in man using a radiotelemetering capsule (Ross, Watson, and Kay, 1963). It is therefore reasonably well established that there is no substantial period of postoperative paralysis of the small intestine.

Studies of the stomach in the postoperative period (Rothnie, Harper, and Catchpole, 1963; Wells, Tinckler, Rawlinson, Jones, and Saunders, 1964) have demonstrated a period of inertia lasting from 24 to 72 hours depending on the type of operation. These findings have been confirmed repeatedly (Nachlas, Younis, Roda, and Wityk, 1972; Neely, 1968). Most of these studies have been radiological observations of barium in the gastrointestinal tract, and, although thestudies have been primarily directed at the stomach, most workers have observed that barium is also held up in the colon. Study of the colon has not been taken further than this one observation.

The present study investigates in more detail the motor behaviour of the colon in the postoperative

Received for publication 12 June 1975. period. Intraluminal pressure readings have been used as an indicator of the return of motor activity in the colon. However, the return of segmental pressure activity in the colon does not necessarily imply the return of propulsive activity, and it is the latter which is of greater clinical importance. Therefore transit of contents through the colon has been measured radiologically using radioopaque markers, and the patterns of gas accumulation in the colon observed at the same time.

\section{The Present Study}

\section{METHODS}

Intraluminal pressures were measured on the right side of the colon using a radiotelemetering capsule (Connell, McCall, Misiewicz, and Rowlands, 1963). Frequency modulated signals were picked up by a multidirectional aerial resting lightly on the abdomen, with a Solartron radio receiver connected to a pen writer. The patient swallowed the capsule on the night before the operation. In almost all cases by the following morning the capsule was in the right half of the colon. Localization to this site was by plain abdominal radiographs and by recording the characteristic pattern of colonic pressure waves which are easily distinguished from pressure patterns in other parts of the gastrointestinal tract (Misiewicz, Waller, Fox, Goldsmith, and Hunt, 1968). Recordings were taken every six hours for 20 minutes at a time until the capsule was passed in the stool or the battery ran out. This was usually between three and five days. 
It has to be assumed that the data were recorded from those patients in whom the capsule remained in the caecum until pressure activity was first detected, an assumption supported by the evidence of daily abdominal radiographs which showed no change in position of the capsule before the return of pressure activity in any of the subjects studied.

Colonic transit was studied by radiological observations of radioopaque pellets (Hinton, Lennard-Jones, and Young, 1969). These are granules of perspex impregnated with barium, each measuring $3 \mathrm{~mm}$ in diameter. The patients swallowed the granules at the same time as the radio capsule. Their transit was observed by noting their position on abdominal radiographs, and secondly by radiological detection of the markers in the stools that were passed. These granules are transported by the colon in the same way as normal faeces and recovery of $80 \%$ of the markers is taken as an acceptable endpoint for the study (Hinton et al, 1969). The gut transit time in normal subjects as described by these authors is from two to four days.

The collection of stools for detecting the granules also allowed recovery of the radio capsules. In each patient the capsule was passed within the time span of passage of $80 \%$ of the granules.

Daily plain supine abdominal radiographs were taken, starting immediately after the operation with a film taken in the recovery room. These films allowed movement of the granules and the radio capsule to be noted, and also afforded an opportunity to observe patterns of gas accumulated in the intestine. A note was made of the day on which the gaseous distension seen radiologically abruptly decreased compared with the previous day.

Throughout each study a careful record was kept of postoperative medication and feeding, of the first passage of flatus, and of the first passage of faeces. Omnopon, $20 \mathrm{mg}$, was used as the postoperative analgesic.

The variables recorded were: (1) the return of segmental pressure activity; (2) the first passage of flatus; (3) the passage of $80 \%$ of the markers in the stools; (4) the time at which colonic distension was seen to decrease on radiographs.

All data were subjected to the Wilcoxon rank test.

\section{THE PATIENTS}

Thirty-nine patients were available for study. In one, the radio capsule was still in the stomach at the time of the operation, a second patient passed the capsule before having the operation, and a third patient found it impossible to swallow the capsule.

The thirty-six remaining patients were studied following various operations. Sixteen had operations involving section of the gastrointestinal tract: of these operations two were hemicolectomies. Eight had intraperitoneal operations not involving section of the gut, four had retropubic prostatectomies, and eight had non-abdominal operations. The types of operation are shown in table I.

Informed consent was obtained from every patient. Because of the need for daily abdominal radiographs, the study was confined to men and to women past childbearing age.

\begin{tabular}{lll}
\hline Operation & No. of Cases & Totals \\
\hline Partial gastrectomy & 6 & \\
Total gastrectomy & 1 & 16 \\
Vagotomy and pyloroplasty & 6 & \\
Cholecystjejunostomy & 1 & \\
Left hemicolectomy & 2 & 8 \\
Cholecystectomy & 6 & \\
Exploratory laparotomy & 2 & 4 \\
Retropubic prostatectomy & & \\
Hernia repair & 1 & 8 \\
Mastectomy & 3 & \\
Thyroidectomy & 1 & \\
Varicose veins & 2 & \\
Transurethral resection & 1 & \\
\hline
\end{tabular}

Table I Types of operation studied

\section{Results}

No untoward effects of the study were experienced by any of the subjects.

\begin{tabular}{llllll}
\hline Operation & No. of Cases & $\begin{array}{l}\text { Average Time } \\
\text { Taken for Return } \\
\text { of Pressure Activity } \\
\text { (hours) }\end{array}$ & $\begin{array}{l}\text { Average Time } \\
\text { Elapsing before } \\
\text { First Passage of } \\
\text { Flatus } \\
\text { (hours) }\end{array}$ & $\begin{array}{l}\text { Average Time } \\
\text { Taken for Passage } \\
\text { of } 80 \% \text { Markers } \\
\text { (days) }\end{array}$ & $\begin{array}{l}\text { Average Time } \\
\text { for Visible Colonic } \\
\text { Decompression on } \\
\text { Radiographs } \\
\text { (days) }\end{array}$ \\
\hline Not abdominal & 8 & 17 & 16 & 3 & 3 \\
Retropubic prostatectomy \\
$\begin{array}{l}\text { Cholecystectomy } \\
\text { Gastrectomy }\end{array}$ & $\mathbf{8}$ & 40 & 40 & $11^{1}$ & 4 \\
Colectomy & 14 & 43 & 64 & 5 & 5 \\
\hline
\end{tabular}

Table II The effect of different operations on the return of colonic motility 
Table II shows the effect of the operations on the return of pressure activity (fig 1), the passage of flatus, the passage of $80 \%$ of the markers and the timing of colon decompression as seen on radiography. Return of segmenting pressures and passage of flatus were delayed in all cases, but more significantly where an abdominal incision was made $(P<$ $0 \cdot 01$ ). This is noticeable even in the extraperitoneal operation of prostatectomy. There was, however, no significant difference between the various abdominal operations.

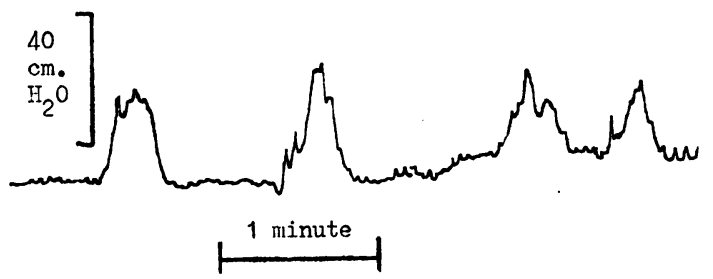

Fig Pressure tracing showing return of colonic activitv after operation.

It is widely believed that the duration of postoperative ileus is directly related to the length of time that the abdomen is open and the intestine exposed. Table III shows the effect of the length of operation in only those cases in which the abdomen was opened. These results do not show any direct relationship between length of operation and duration of ileus $(P>0.05)$.

A further factor commonly believed to influence postoperative ileus is excessive postoperative analgesia. Table IV shows the relation between the number of doses of Omnopon given and the duration of ileus. This does not show any significant relationship between analgesics given and the duration of ileus $(P>0.05)$.

\section{Discussion}

It is clear from previous studies (Wells et al, 1964; Rothnie et al, 1963) that operations affect different parts of the alimentary tract in different ways. Gastric stasis persists for $\mathbf{4 8}$ to $\mathbf{7 2}$ hours, small bowel impairment is minimal, while colonic stasis has not previously been studied.

The present study shows that following laparotomy colonic pressure activity first occurs after 40 to 48 hours and that even with operations other than abdominal activity is not usually recorded until 16 hours after operation.

Segmenting pressure activity in the colon does not imply propulsion. Most colonic activity is made up of mixing movements while propulsive contractions are sporadic. It is not surprising, therefore, to find that passage of flatus usually occurs some hours after the onset of initial pressure activity.

It has been repeatedly stated in the past that the duration of postoperative ileus is proportional to the severity of the surgical trauma and also to the type of operation (Neely, 1969; Aird, 1957). It was therefore surprising to find that the length of operation had little or no effect on the duration of colonic stasis in this series. After some operations lasting over three hours, colonic activity returned within $\mathbf{4 0}$ hours, while in some operations lasting only one hour, activity did not return for over 60 hours. Prolonged exposure and handling of the gut do not therefore seem to be such important factors in the duration of postoperative colonic ileus as had previously been thought.

\begin{tabular}{|c|c|c|c|c|}
\hline $\begin{array}{l}\text { Length of Operation } \\
\text { (hours) }\end{array}$ & $\begin{array}{l}\text { Average Time Taken } \\
\text { for Return of } \\
\text { Pressure Activity } \\
\text { (hours) }\end{array}$ & $\begin{array}{l}\text { Average Time Elapsing } \\
\text { before First Passage of } \\
\text { Flatus } \\
\text { (hours) }\end{array}$ & $\begin{array}{l}\text { Average Time Taken } \\
\text { for Passage of } 80 \% \text { of } \\
\text { Markers } \\
\text { (days) }\end{array}$ & $\begin{array}{l}\text { Average Time for Visible } \\
\text { Colonic Decompression } \\
\text { on Radiographs } \\
\text { (days) }\end{array}$ \\
\hline $\begin{array}{l}1-2 \text { hours } \\
2-3 \text { hours } \\
3-4 \text { hours }\end{array}$ & $\begin{array}{l}55 \\
42 \\
39\end{array}$ & $\begin{array}{l}65 \\
57 \\
70\end{array}$ & $\begin{array}{l}6 \\
5 \\
7\end{array}$ & $\begin{array}{l}4 \\
5 \\
5\end{array}$ \\
\hline
\end{tabular}

Table III The effect of length of operation on the return of colonic motility

\begin{tabular}{|c|c|c|c|c|}
\hline $\begin{array}{l}\text { Total No. of Doses of } \\
\text { Postoperative Analgesic }\end{array}$ & $\begin{array}{l}\text { Average Time Taken } \\
\text { for Return of } \\
\text { Pressure Activity } \\
\text { (hours) }\end{array}$ & $\begin{array}{l}\text { Average Time Elapsing } \\
\text { before First Passage } \\
\text { of Flatus } \\
\text { (hours) }\end{array}$ & $\begin{array}{l}\text { Average Time Taken } \\
\text { for Passage of } 80 \% \\
\text { Markers } \\
\text { (days) }\end{array}$ & $\begin{array}{l}\text { Average Time for Visible } \\
\text { Colonic Decompression } \\
\text { on Radiographs } \\
\text { (days) }\end{array}$ \\
\hline $\begin{array}{l}2-4 \\
4-6 \\
6-8 \\
>8\end{array}$ & $\begin{array}{l}38 \\
34 \\
62 \\
49\end{array}$ & $\begin{array}{l}66 \\
65 \\
60 \\
58\end{array}$ & $\begin{array}{l}6 \\
6 \\
5 \\
6\end{array}$ & $\begin{array}{l}4 \\
5 \\
4 \\
5\end{array}$ \\
\hline
\end{tabular}

Table IV The effect of postoperative analgesia on the return of colonic motility 
It is well established in animals that postoperative ileus results from sympathetic inhibition mediated by a spinal reflex and this is generally accepted as being true for man as well. The present study suggests that afferents in the gut and visceral peritoneum are not as important as had previously been assumed. It seems probable therefore that the afferent side of the reflex originates in the parietal peritoneum. This view is further supported by the finding of prolonged colonic ileus following retropubic prostatectomy, and the well known occurrence of ileus following retroperitoneal trauma.

Morphine has been shown in the past to stimulate colonic motility (Painter and Truelove, 1963) although it has also been noted that it reduces colonic transport (Adler and Templeton, 1940). The present study does not demonstrate any influence of Omnopon on the return of colonic segmental pressure activity, passage of flatus or propulsion of faeces. Neely (1969) reported that the injection of analgesics resulted in colonic pressure activity within 20 minutes of the injection, and suggested that the two events were causally related. This observation has not been confirmed in the present study. In 12 cases where pressure recordings were taken within one hour of an injection of morphine on only one occasion was pressure activity seen. The injections did not therefore appear to initiate response in a colon in which activity had not already returned spontaneously.

Daily radiographs of the abdomen have made it possible to observe the pattern of gas accumulation in the gut. In the normal person there is usually little gas in the small intestine, and this is true also in the postoperative phase. All accumulated gas is found either in the stomach or in the colon. Since small intestinal motility is virtually normal postoperatively, any gas entering the small gut from the stomach is rapidly passed on into the colon which passively distends. The capacity of the colon for accepting this gas is considerable, and even in the presence of gross abdominal distension radiographs will show that the distension is confined to the colon. Should gas appear in the small gut then this implies some pathological influence on the small gut such as peritonitis or mechanical obstruction.

Many patients complain of wind pains after abdominal surgery. These could arise either from the small or the large intestine. Small intestinal colic could arise because of a functional obstruction caused by the inert colon. If this were so, however, then the small gut would become distended and this is never seen on radiographs. It seems that colonic ileus does not act as an obstruction to the small intestine, and seems likely therefore that the pains arise from the colon. The pains that are felt coincide with the return of colonic motility, and probably represent attempts at contraction by a colon that is already distended.

The delay in passage of $80 \%$ of the markers in patients compared with normal subjects is only in part due to the temporary impairment of colonic activity following laparotomy, for colonic transit is also delayed by recumbency and this factor probably plays a part in the slow transit of faeces after abdominal operations.

This work was carried out in the Department of Gastroenterology of the Central Middlesex Hospital and the Department of Surgical Studies of the Middlesex Hospital Medical School. I am most grateful to Dr J. J. Misiewicz for his help and advice, and to the surgeons whose patients were studied.

\section{References}

Adler, H. F., and Templeton, R. D. (1940). Correlation of activity and transportation in colon of dog. Amer.J. Physiol, 128, 514-520.

Aird, I. (1957). A Companion in Surgical Studies, 2nd ed., p. 824. Livingstone, Edinburgh.

Baker, L. W., and Webster, D. R. (1968). Postoperative intestinal motility. Brit. J. Surg., 55, 374-378.

Connell, A. M., McCall, J., Misiewicz, J. J., and Rowlands, E. N. (1963). Observations on the clinical use of radio pills. Brit. med. J., 2, 771-774.

Hinton, J. M., Lennard-Jones, J. E., and Young, A. C. (1969). A new method for studying gut transit times using radio opaque markers. Gut, 10, 842-847.

Misiewicz, J. J., Waller, S. L., Fox, R. H., Goldsmith, R., and Hunt, T. J. (1968). The effect of elevated body temperature and of stress on the motility of the stomach and colon in man. Clin. Sci., 34, 149.

Nachlas, M., Younis, M. T., Roda, Claro Pio, and Wityk, J. J. (1972). Gastrointestinal motility studies as a guide to postoperative management. Annals Surg., 175, 510-522.

Neely, J. A. C. (1968). An investigation into ileus and the autonomic control of gastrointestinal motility. MS Thesis, London University.

Neely, J. (1969). The effects of analgesic drugs on gastro-intestinal motility in man. Brit. J. Surg., 56, 925-929.

Painter, N. S., and Truelove, S. C. (1963). Potential dangers of morphine in acute diverticulitis of the colon. Brit. med. J., 2, 33-34.

Ross, B., Watson, B. W., and Kay, A. W. (1963). Studies on the effect of vagotomy on small intestinal motility using the radiotelo metering capsule. Gut, 4, 77-81.

Rothnie, N. G., Harper, R. A. K., and Catchpole, B. N. (1963). Early postoperative gastrointestinal activity. Lancet, 2, 64-67.

Tinckler, L. F. (1965). Surgery and intestinal motility. Brit. J. Surg., $52,140-150$.

Wells, C., Tinckler, L., Rawlinson, K., Jones, H., and Saunders, J. (1964). Postoperative gastrointestinal motility. Lancet, 1, 4-10. 